DOI: $\underline{10.17805 / g g z .2019 .4 .4}$

\title{
Биотехнологии, тело и спорт: где границы свободы?
}

\author{
Р. Р. Белялетдинов, О. В. Попова \\ Институт философии РАН
}

В статье рассматриваются различные типы свободы в профессиональной деятельности спортсмена. Показано, что возможны два типа самореализации персональной автономии в спортивной деятельности. Первый тип автономии связан с биомедицинскими ограничениями (выраженными в антидопинговом регулировании), гарантирующими защиту от рисков и идеализированную естественность спортсмена в проявлении его свободы при достижении высоких спортивных результатов. Второй тип персональной автономии в спорте, напротив, выражен в развитии конструктивистского и экстремального представления о теле спортсмена, безграничных возможностях его модификации и соверменствования доступными биомедицинскими средствами. Граница между первым и вторым типом спортивной автономии формируется не только под регулятивным воздействием института спорта, но и, что не менее важно, зависит от личностной саморегуляции спортсменов, принимающих на себя самые разнообразные риски (недостижения спортивного результата, угрозы здоровью, ограничения личностного потенциала).

Важно отметить, что рекорды, полученные в рамках второго типа реализачии автономии спортсмена, расширяют представления о естественных физических способностях и зачастую рассматриваются как проявление морфологической свободы человека, направленной на управление и инструментализацию собственного тела. Однако официально, при доказательстве использования допинга, такие рекорды не только не получают признание, но и негативно влияют на имидж спортсмена и его профессиональную карьеру.

В статье на примере исследования возможностей разграничения терапии и улучшения в таких сферах жизни, как спорт и образование, поставлена проблема значения персональной автономии для определения антропологической нормы в профессиональной деятельности. Сделан вывод о том, что возрастающие требования к достижению спортивных результатов при неизменном запасе прочности человеческой природы стимулируют запрос на расширение персональной автономии. Современный спортсмен вынужден не только играть за себя, команду или страну естественными усилиями, но и участвовать в фармакологических и генетических играх. В то время как об- 
щество очерчивает объективные границы свободы в спорте, а спортивная этика разрабатьвает жесткие правила поведения спортсмена, сами спортсмены также формируют и реализуют свое личное представление о физических возможностях собственного тела через признание персонального горизонта риска.

Ключевые слова: биотехнологии; биоэтика; автономия; риски; спорт; технологии улучшения человека; биотехнологическое конструирование человека; границь свободы

\section{Biotechnologies, Body and Sport: Where Are the Boundaries of Freedom? R. R. Belyaletdinov, O. V. Popova Institute of Philosophy, Russian Academy of Sciences}

The article discusses various types of freedom in professional athletic activity. It is shown that two types of self-realization of personal autonomy in sports activities are possible. The first type of autonomy is associated with biomedical restrictions (expressed in anti-doping regulations), which guarantee protection against risks and an idealized naturalness of an athlete in manifesting their freedom while achieving high sports results. The second type of personal autonomy in sport, on the contrary, is expressed in the development of a constructivist and extreme view of the athlete's body, the unlimited possibilities of its modification and enhancement by available biomedical tools. The boundary between the first and second types of sports autonomy is formed not only under the regulatory impact of sport as an institution, but, equally important, depends on the personal selfregulation of athletes who take a variety of risks (failure to achieve sports results, threats to health, limiting personal potential).

It is important to note that records obtained in the framework of the second type of realization of an athlete's autonomy expand the visions of natural physical abilities and are often considered as a manifestation of human morphological freedom aimed at controlling and instrumentalizing one's own body. However, officially, when the fact of doping is proved, such records not only do not receive recognition, but also negatively affect the image of athletes and their professional careers.

In the article, we study the possibilities of differentiation between therapy and enhancement in such areas of life as sports and education and define the problem of the significance of personal autonomy for determining the anthropological norm in professional activity. It is concluded that the increasing requirements for the achievement of sports results with a constant safety margin of human nature stimulates a request for the expansion of personal autonomy. The contemporary 
athlete is faced with the need not only to play for themselves, their team, and country making natural efforts, but also to be included in pharmacological and genetic games. While society delineates the objective boundaries of freedom in sports and sports ethics develops strict regulations of athlete behaviour, athletes themselves also form and implement their own personal understanding of the physical capabilities of their own body through recognizing their personal risk horizon.

Keywords: biotechnologies; bioethics; autonomy; risks; sport; human enhancement technologies; biotechnological human design; boundaries of freedom

\section{ВВЕДЕНИЕ}

Когда речь заходит о спорте как проявлении свободы человека в преодолении своих физических возможностей, приходится говорить и об ограничениях - естественных, культурных и этических. Во многом спорт является не только публичным зрелищем, но и сферой жизни, где человек обретает самовыражение и самореализацию, добивается публичного признания. В последние десятилетия в связи с принятием жестких антидопинговых правил профессиональный спорт превращается в идеализированный образец телесной нормальности, которую тщательно охраняют специальные лаборатории и врачи. В то время как в обычной жизни люди все чаще пользуются многообразными когнитивными и физическими стимуляторами, многие из которых доступны даже без рецепта врача, спортсмены обязаны соблюдать биомедицинские ограничения, гарантирующие идеализированную естественность, которая должна обеспечивать подлинность рекордов и результатов.

Вместе с тем существует и другой тип спортивной свободы, неофициальный, связанный с конструктивистским представлением о теле спортсмена. Нередко он приводит к допинговым скандалам и дисквалификациям. Выбор между подлинным и сконструированным определяет сегодня судьбы тысяч спортсменов, избирающих способ достижения спортивного результата.

Активно защищаемые в спорте правила и нормативы здоровья и телесности оказываются под ударом допинговых скандалов вовсе не случайно. Некоторые спортсмены не признают навязываемые им в принудительном порядке границы телесности и рассматривают спортивный результат как проявление личной свободы и победы над ограничениями своего тела.

Так возникает два типа свободы в спорте: свобода спортивного достижения, полученного спортсменами в результате раскрытия их личных физических задатков, данных природой, и свобода достижения, ставшего возможным благодаря использованию различных биотехнологических и фармакологических средств. Последний тип рекордов также расширяет представления о физических способностях и может рассматриваться как проявление морфологической свободы человека, направленной на управление и инструмента- 
лизацию собственного тела. Однако официально при доказательстве использования допинга такие рекорды не только не получают признания, но и негативно влияют на имидж спортсмена и его профессиональную карьеру.

Важно, чтобы риски негативного воздействия допинга на здоровье спортсменов были доказанными, а отдельные препараты, попадающие в перечень допинговых лекарственных средств, не превращались в фактор, сдерживающий нацеленность спортсменов на преодоление уже поставленных рекордов. Вероятно, учитывая факты использования допинга и конвенциональность многих препаратов, вред от которых не всегда доказан, а польза очевидна, нельзя придерживаться крайне узкого взгляда на проблему допинга и игнорировать, по сути, естественные причины, которые заставляют спортсменов нарушать антидопинговые правила.

\section{ПРОБЛЕМА ТЕРАПИИ И УЛУЧШЕНИЯ}

Регулирование биомедицинских аспектов прав человека, определение границ его автономии в ситуациях, связанных с использованием биотехнологий по отношению к человеческому телу, уважение достоинства и общественных ценностей составляют содержание современной биоэтики. Одна из ее целей - определение границ персональной автономии с учетом принципов справедливости и блага. Особенностью биоэтики является ее открытость к экспериментированию с различными типами аргументации (Jonsen, 2004: 40-47). Так, биоэтика «не столько формальная дисциплина, сколько пересечение многих дисциплин, входящих в более широкий общественный дискурс» (ibid: 49; перевод наш. - Р. Б., О. П.). В биоэтике формируются критерии биомедицинской нормы здоровья как комплексного явления, включающего не только биологические показатели, но и личностные взгляды, воображение и автономию, определяющие отношения к этой норме человека, но также сохраняется возможность обсуждать некоторые персоналистические детали, оставляя выбор за самим человеком.

Между тем очевидно, что развитие биотехнологий ставит вопрос о сущности человека, его непреходящей ценности, которая раскрывается в процессе соревнования и имеет для спорта особое значение, и в общем-то служит тем ориентиром, к которому стремятся спортсмены, ставя рекорды.

Если попробовать представить идеальный образ человека, то автономия, идентичность и личность (Miah, 2004: 88) - это элементы, из которых складывается его деятельность. Хотя на практике профессиональные спортсмены в своих действиях стремятся к фактическому спортивному результату, истинным регулятивом для них служат не только формальные, но и естественные границы: личные, социальные и телесные. 
Как известно, антидопинговые программы возникли вовсе не из-за беспокойства за качество соревнований и их справедливость, а в результате случаев гибели спортсменов в результате приема допинга. Впоследствии для обоснования антидопинговой идеологии потребовалось жестко разделить естественное и улучшенное тело. Эти условия также можно переформулировать через определение границы, разделяющей лечение и улучшение. Понятие «болезнь» опирается на биологический детерминизм, рассматривающий ее как отклонение от нормальных биологических показателей организма, а лечение - как возвращение к известным в качестве нормы показателям. В теории социального конструктивизма (ibid: 99) расстройства превращаются в болезнь под воздействием социальных причин (Юдин, 2000; Тищенко, 2003). Они инспирированы не только биологическими причинами, но также и социальными факторами, и в некотором смысле являются социальной конструкцией.

Расстройство может оцениваться противоположно: как здоровье в медицинской оптике и как болезнь - в социальной: согласно медицинской норме низкий рост расценивается как здоровье, но в социальных отношениях люди, обладающие ростом ниже распространенной нормы, испытывают сильный дискомфорт, подавленность, неуверенность в себе, полагая, что низкий рост - источник страданий и заболевание. Они здоровы по медицинским показателям, но многие из них чувствуют себя больными, так как в глазах своих друзей и знакомых низкий рост может рассматриваться как физический недостаток.

Граница между болезнью и здоровьем, основанная на идее блага здоровья, понятого в рамках биологического детерминизма нормы, достаточно однобока и не учитывает социальную природу многих болезней. Спортсмены оказываются в похожей ситуации: если не удается добиться спортивного результата, это обстоятельство может рассматриваться как существенный физический недостаток и изъян, с которым следует бороться. Так персональное представление о границе, разделяющей заболевание и здоровье, сдвигается, и неспособность повысить спортивный результат воспринимается как болезнь.

\section{ОПРЕДЕЛЕНИЕ ГОРИЗОНТА \\ БИОТЕХНОЛОГИЧЕСКИХ РИСКОВ}

Общество в лице антидопинговых служб в целом исходит из патерналистской концепции защиты здоровья спортсменов. Существует как минимум три типа соотношения автономии и блага (Cohen, 2019). Первый тип связан с разделением блага и автономии, а выбор существует по принципу исключения - либо автономия, либо благо. Наиболее информированные люди более склонны к автономным решениям, в то время как менее интел- 
лектуальные опираются на благо и готовы ограничивать свои желания ради представлений о благе, которые черпаются от врачей или консультантов. Второй тип - это делиберация и взаимное определение блага и автономии. В этом дискурсе благо не ограничивает автономию, а предстает в различных модусах. Например, в модусе наилучшего выбора из комплекса возможностей (среди которых выбор, соответствующий благу, - лишь один из многих), архитектуры подаваемой информации. Свободный выбор при этом не ограничивается и сосуществует наравне с выбором блага. Третий тип взаимоотношения автономии и блага - отсутствие границ между этими двумя принципами. Все, что автономно, является благом и, напротив, все, что есть благо, является автономией. Этот тип автономии можно рассматривать либо как либертарианство, либо, наоборот, интерпретировать в духе патернализма как доверительный внешний выбор в результате консультаций, когда рекомендации следовать тому или иному образу действий, который оценивается как благо, полностью принимаются как автономный выбор.

Регуляторы берут на себя ответственность за здоровье спортсменов, тщательно отслеживая случаи применения субстанций и биомедицинских технологий, попадающих в категорию допинга, действуя прежде всего в интересах самих спортсменов, спасая их от возможной гибели из-за физических перегрузок. Действия регулятора часто можно классифицировать по первому типу соотношения автономии и блага - как ограничение автономии в пользу блага. Однако такой подход нельзя назвать ни современным, ни эффективным. Напротив, использование первого типа соотношения автономии и блага, причем в интерпретации этого подхода в пользу принципа блага, ведет к появлению серых зон, где принцип блага используется в качестве инструмента контроля спортсменов.

Между тем риски, связанные с применением допинга, - не единственные, существует множество других рисков, с которыми сталкиваются спортсмены: профессиональные травмы, вероятность появления хронических заболеваний из-за длительных физических перегрузок. Эти риски не носят публичного характера, но они оказывают существенное влияние на траектории жизни спортсменов. Принятие этих рисков входит в компетенцию автономии спортсменов. Таким образом de facto спортсмены вынуждены балансировать между угрозами своему здоровью из-за физических перегрузок и благом, которое выражается в следовании нормативам антидопинговой политики. Вполне закономерно, что регулярные допинговые скандалы и строгость антидопинговых служб в преследовании спортсменов являются прямым результатом того, что спортсмены не признают ограничение своей автономии в принятии на себя еще больших спортивных рисков, чем те, которые делегированы спортсменам обществом. Реализация третьего типа соотношения бла- 
га и автономии возникает либо из-за переоценки значения собственного выбора, который обращается во благо, либо является результатом влияния тренера, который нередко выступает консультантом и может влиять на подбор нагрузок, а также препаратов, которые принимает спортсмен. Описание деятельности последнего лишь в рамках концепции честной игры недостаточно точно. Различные поведенческие стратегии включают разные типы взаимодействия автономии и блага и во многих ситуациях спортсмен вынужден рассматривать собственную автономию как источник блага, а не следовать внешним принципам и правилам, в которых благо представлено как модель поведения.

В этой связи представляется, что роль автономии спортсменов в определении того, до какой степени приемлемо расширение возможностей тела с помощью различных биомедицинских стратегий, существенна. Нельзя рассматривать спорт лишь в рамках первого типа соотношения автономии и блага, где благо всегда вытесняет и ограничивает автономию. Спортивная деятельность, даже если она принудительно ориентируется на нормативы, выстроенные по принципу следования естественным стандартам здоровья, неизбежно коррумпируется как под воздействием медикализации спорта, так и в результате вынужденного расширения автономии на решения, которые либо не регулируются антидопинговыми правилами, либо принимаются под внешним влиянием, оказываемым на спортсмена тренерами и консультантами.

Является ли сутью спорта личный подвиг и спортивный результат, либо это публичная сфера, где важны не только правила игры, но и правила, фиксирующие параметры тела? И если показатели тела так важны, то следует ли, стремясь к справедливости, принимать во внимание физические данные спортсменов - не только весовую категорию, но и другие параметры, например, способность переносить физические нагрузки или объем легких, чтобы соревнования были действительно честными, а шансы спортсменов на победу равными? Либо необходимо расширить автономию спортсменов в выборе биотехнологических стратегий, позволяющих добиваться более высоких результатов, запретив лишь те биотехнологические решения, которые могут привести к доказанной потенциальной гибели? Ответы на эти вопросы лежат в понимании того, как следует относиться к спортсмену — как к телу или как к автономной личности, способной определить собственный горизонт риска.

Но следует также иметь в виду, что стратегии биотехнологического улучшения - развитие когнитивных способностей, устойчивости к стрессу, физическим нагрузкам - становятся практикой обычной, неспортивной жизни и входят в сферу автономии многих людей, чьи профессии связаны с 
физическими и эмоциональными перегрузками. Ограничение патернализма, замена жесткого патернализма его мягкими формами, где принято давать рекомендации, а не предписания, - особенность современного развития биомедицины, ставшей «территорией высокой социальной и этической напряженности» (Вархотов и др., 2018: 81). Оградить спорт от влияния биотехнологий и тенденции расширения персональной автономии с каждым десятилетием будет сложнее, еще более сложно демонстрировать, что антидопинговые программы не являются инструментом репрессий и давления, чуждым самой идее справедливого спорта.

\section{МЕДИКАЛИЗАЦИЯ И СПОРТ}

Современная жизнь предъявляет к индивиду очень жесткие требования в его профессиональной жизни. Конкурентные отношения во всех сферах деятельности приводят к поиску средств, обещающих успех, дающих надежду выдержать борьбу в профессиональной гонке. Медикализация современной жизни способствует развитию тенденции оценки состояния организма, не способного адаптироваться к профессиональным требованиям своей среды, как физического расстройства, заболевания. При этом осуществляется поиск наиболее легких путей адаптации, например, с помощью медикаментозных средств (допинга в спорте).

Целый ряд профессий, требующих повышенной концентрации внимания (можно вспомнить о проводящих сложные операции хирургов или дальнобойщиках), формирует потребность в развитии новых технологий, направленных на реализацию данной цели. Практические шаги в этом направлении уже сделаны: для человека стали привычными многие стимуляторы, такие как кофе или энергетические напитки, позволяющие в какой-то мере адаптироваться к быстрому ритму жизни и возрастающей нагрузке на работе. Так, дальнобойщикам может показаться эффективным прием быстродействующих лекарственных средств, позволяющих усилить их способность концентрации на дороге. Это оказывается гораздо более быстрым путем, чем создание соответствующих условий труда. Для выполнения определенных профессиональных функций зачастую требуется не столько личность, сколько идеальный биоробот, адаптирующийся под запросы среды и способный быстро решать те или иные задачи.

Современному спортсмену фармакологические компании и развивающиеся генетические технологии также открывают похожие перспективы: возрастающие требования к достижению спортивных результатов при неизменном запасе прочности человеческой природы стимулируют поиск средств увеличения физических возможностей. Современный спортсмен поставлен перед необходимостью не только играть за себя, свою команду, страну, поль- 
зуясь своими естественными возможностями, но и включаться в фармакологические, генетические игры, чтобы сохранить себя как живого индивида в контексте возрастающей состязательности, требующей максимальной отдачи.

На фоне взаимосвязанных тенденций развития практик улучшения в таких сферах жизни, как спорт, трудовые отношения, образование, возникает проблема определения антропологической нормы в профессиональной деятельности. Лица, не использующие усилители и, следовательно, не соответствующие новым нормам профессиональной деятельности, могут подвергаться дискриминации и стигматизирующей оценке. И если в сфере образования распространенной практикой вполне способна стать зависимость от когнитивных усилителей, то в спортивной сфере невидимый, нераспознаваемый допинг или усиленное технологиями тело спортсмена способны привести к желаемым высоким спортивным результатам. Предпосылки к этому активно складываются в настоящее время. Нацеленность медицины и биотехнологий на расширение человеческих способностей станет не менее важной, чем их ориентация на восстановление здоровья.

П. Вирилио отметил в работе «Открытые небеса», что наше состояние «не будет отличаться от того, в каком находится любой калека», которого можно назвать «моделью нового человека» (цит. по: Булатов, 2006: 8; см. также: Булатов, 2005: Электронный ресурс). Технологический мир вызвал к жизни появление модели «человека с протезом». Под «протезом» может пониматься и усиливающий физические качества человека технологический артефакт, и резко повышающий когнитивные свойства индивида фармакологический препарат, и генетический допинг, повышающий выносливость и спортивные способности.

Классическим примером дихотомии улучшения (терапии) и траекторий развития форм допинга является случай с бегуном Оскаром Писториусом, шестикратным чемпионом летних Паралимпийских игр. В связи с ампутацией конечностей ему были прикреплены бионические протезные устройства. Созданные с помощью высоких технологий, по мнению ряда критиков, они давали ему неоспоримые преимущества перед другими спортсменами, позволяя бегать быстрее, что нарушало дух честной игры спортивных соревнований. В результате Писториус был отстранен от участия в играх с обычными спортсменами. Впоследствии, однако, Спортивный арбитражный суд заявил, что преимущества Писториуса сочетаются с ущербом для его здоровья и неудобствами, возникающими от имеющихся протезов, в том числе связаны с техническими особенностями их использования во время спортивных соревнований, например, более медленным стартом. Оправданный Писториус позднее принимал участие не только в Паралимпийских, но и в Олимпий- 
ских играх. Его неоднозначная фигура породила множество вопросов, центральным из которых, пожалуй, можно считать вопрос о возможности «честной» игры в эпоху технологий.

Развитие технологий бионических протезных устройств, изначально предназначавшихся лицам с ограниченными возможностями здоровья в качестве своеобразной терапии, вызвало прецедент деформации логики олимпийского движения и открыло возможности для наступления эры бионических спортсменов. При этом человечество может столкнуться со следующей тенденцией: чем больше внимания будет уделяться разработке технологических средств лечения и улучшения для спортсменов с ограниченными возможностями здоровья, тем значительней будет увеличение спектра возможностей у спортсменов, не имеющих ограничений по здоровью. На оценку этих возможностей, появление которых прежде всего обусловлено действием технологий невидимого конструирования человеческого тела, очевидно, будут направлены сложные этические алгоритмы (в том числе механизмы выявления различных форм допинга). По словам Э. Миа, «мы не можем, однако, допускать, что находящаяся в стадии становления эпоха бионического спортсмена будет хорошо подходить для людей с ограниченными возможностями. В то время как новые технологии могут обеспечить преобразования, которые превзойдут возможности так называемых дееспособных атлетов, последующие нововведения могут быть доступны этим спортсменам, которые смогут еще больше видоизменять границы сравнения. Возьмем, к примеру, перспективы более крепких сухожилий, использование лазерной коррекции зрения и даже элективные хирургические вмешательства, направленные на укрепление организма» (Miah, 2008: Электронный ресурс; перевод наш. - Р. Б., O. II.).

В целом этическая оценка перспектив вторжения в природу человека, связанная с разграничением терапии и улучшения, неизменно упирается в философские проблемы. По справедливому замечанию Б. Г. Юдина, «когда мы даем тот или иной ответ на вопрос, носит некоторое технологическое воздействие на человека терапевтический характер или же оно направлено на улучшение человека (естественно, улучшение, понятое в евгеническом или, если угодно, трансгуманистическом смысле), мы опираемся при этом на определенное понимание того, “что есть человек”» (Юдин, 2011: 18). Это высказывание применительно к оценке развития технологий в спорте можно перефразировать следующим образом: ответ на вопрос о границах улучшения или терапии всегда будет иметь дело с содержанием, которое мы вкладываем в понятие «спортсмен». Будет ли оно в будущем подразумевать коннотации, связанные с протезированным человеком или генетически усовершенствованным существом, скорее всего, зависит от социально-культурных 
предпочтений человека будущего и не в меньшей степени от успешности дальнейшего проникновения биополитики в сферу физической культуры и спорта.

Так, обсуждаемые уже сегодня возможности применения генетических технологий (генной терапии) для увеличения мышечной массы представляют собой пример трансляции биомедицинских технологий, изначально направленных на лечение заболеваний, в контексте улучшения человека. Изначально такой вид помощи являлся медикаментозной терапией мышечной дистрофии, саркопении, ВИЧа, СПИДа и раковой кахексии. Однако данный вид помощи способен открыть новые неоднозначные в этическом отношении перспективы как для современного бодибилдинга, так и для всего спорта в целом: столь необходимая спортсмену повышенная мышечная масса будет формироваться не благодаря длительным и зачастую непосильным тренировкам, сопровождаемым усиленным вниманием к нагрузкам для собственного тела, но посредством генетических манипуляций, задающих план развития для физически выносливого, атлетически сложенного индивида. Сквозь генетическую оптику человечество будет иметь дело с культивированием «внутренней» красоты и силы, которые технологически неизбежно обретут свой внешний план и станут технологической основой будущих спортивных результатов.

Развитие технологий улучшения создает основания для развития кризиса спорта с его стремлением к честной игре (fair play). Использование генетического допинга у спортсменов означает модификацию спорта как сферы профессиональной деятельности, где формат справедливой конкурентоспособности трансформируется в биотехнологические бои.

\section{ЗАКЛЮЧЕНИЕ}

Следует принимать во внимание то обстоятельство, что спортсмены не только представляют страны, выступают за сборные и связаны социальными обязательствами, но также реализуют возможности не только своего тела, но и своей личности. Общество накладывает профессиональные и объективные границы свободы в спорте, спортивная дисциплина предлагает правила для каждого конкретного вида спорта, спортивная этика - жесткие правила поведения спортсмена. Но и сами спортсмены формируют свое личное поле свободы для собственного тела через определение персонального горизонта риска, без которого само существование спорта было бы невозможно и лишено смысла либо превратилось бы в театральное действие. Роль автономии спортсмена в выборе стратегии тренировок, ритмов нагрузок и способов психологической подготовки к выступлениям коррелирует с социальной средой, 
в которую погружен спортсмен, и с его личными горизонтами риска, в которых также определяется его телесность.

Возникновение Всемирного антидопингового агентства (ВАДА) во многом связано с необходимостью защищать спортсменов от смертельных форм спортивных перегрузок, которые становятся возможны в результате использования допинга. Вместе с тем современное антидопинговое движение является не только формой охраны здоровья спортсменов, но и довольно жестким ограничителем спортивного движения в его ключевой идее - обретение новых границ телесной свободы, которые должны складываться с учетом приоритета персональной автономии.

\section{СПИСОК ЛИТЕРАТУРЫ}

Булатов, Д. (2005) Радиоуправляемые насекомые-киборги [Электронный ресурс] // Независимая газета. 23 марта. № 56 (3452). URL: http:// ng.ru/science/2005-03-23/15 kiborg.html [архивировано в WaybackMachine] (дата обращения: 11.08.2019).

Булатов, Д. (2006) Коэволюция, избыток, дестабилизация. О современных стратегиях в области science art // Логос. № 4 (55). С. 4-19.

Вархотов, Т. А. и др. (2018) Технонаука и этос ученого: контуры этики биобанкинга глазами российского научного сообщества (по результатам опроса специалистов в области биомедицины и смежных видов деятельности) / Т. А. Вархотов, К. Ю. Аласания, Е. В. Брызгалина, С. М. Гавриленко, А. Л. Рыжов, Е. М. Шкомова // ПРАКСЕМА. Проблемы визуальной семиотики. № 4 (18). С. 61-83. DOI: 10.23951/2312-7899-2018-4-61-83

Тищенко, П. Д. (2003) Здоровье: философско-антропологический аспект // Здоровье человека: социогуманитарные и медико-биологические аспекты / под ред. Б. Г. Юдина. М. : Институт человека РАН. 288 с. С. 106-113.

Юдин, Б. Г. (2000) Здоровье: факт, норма и ценность // Мир психологии. № 1 (21). С. 54-68.

Юдин, Б. Г. (2011) Человек как объект технологических воздействий // Человек. № 3. С. 5-20.

Cohen, S. (2019) The logic of the interaction between beneficence and respect for autonomy // Medicine, Health Care and Philosophy. Vol. 22. Issue 2. P. 297-304. DOI: $10.1007 / \mathrm{s} 11019-018-9876-4$

Jonsen, A. R. (2004) The history of bioethics as a discipline // Handbook of bioethics: Taking stock of the field from a philosophical perspective / ed. by G. Khushf. N. Y. ; Boston ; Dordrecht ; L. ; M. : Kluwer Academic Publishers. 573 p. P. 31-51. (Philosophy and Medicine, vol. 78). DOI: $\underline{10.1007 / 1-4020-2127-5 ~} 2$

Miah, A. (2004) Genetically modified athletes: Biomedical ethics, gene doping and sport. L. ; N. Y. : Routledge. xviii, 208 p. 
Miah, A. (2008) Paralympics 2.0 [Электронный pecypc] // Professor Andy Miah. June 6. URL: https://andymiah.net/blog/2008/06/06/paralympics-20 [архивировано в WaybackMachine] (дата обращения: 12.08.2019).

Дата поступления: 14.08.2019 2.

\section{REFERENCES}

Bulatov, D. (2005) Radioupravliaemye nasekomye-kiborgi [Radiocontrolled cyborg insects]. Nezavisimaia gazeta, March 23, no. 56 (3452). [online] Available at: http://www.ng.ru/science/2005-03-23/15 kiborg.html [archived in WaybackMachine] (accessed 11.08.2019). (In Russ.).

Bulatov, D. (2006) Koevoliutsiia, izbytok, destabilizatsiia. O sovremennykh strategiiakh v oblasti science art [Coevolution, excess, destabilization. On modern strategies in the field of science art]. Logos, no. 4 (55), pp. 4-19. (In Russ.).

Varkhotov, T. A. et al. (2018) Tekhnonauka i etos uchenogo: kontury etiki biobankinga glazami rossiiskogo nauchnogo soobshchestva (po rezul'tatam oprosa spetsialistov v oblasti biomeditsiny i smezhnykh vidov deiatel'nosti) [Technoscience and the scientific ethos: Outlines of the ethics of biobanking through the eyes of the Russian scientific community (Based on a survey of specialists in the field of biomedicine and related research activities)] / T. A. Varkhotov, K. Yu. Alasaniia, E. V. Bryzgalina, S. M. Gavrilenko, A. L. Ryzhov and E. M. Shkomova. PRAKSEMA. Problemy vizual'noi semiotiki, no. 4 (18), pp. 61-83. (In Russ.). DOI: 10.23951/2312-7899-2018-4-61-83

Tishchenko, P. D. (2003) Zdorov'e: filosofsko-antropologicheskii aspekt [Health: Philosophical and anthropological aspect]. In: Zdorov'e cheloveka: sotsiogumanitarnye $i$ mediko-biologicheskie aspekty [Human's health: Sociohumanitarian, medical and biological aspects] / ed. by B. G. Yudin. Moscow : Institute of Man, RAS. 288 p. Pp. 106-113. (In Russ.).

Yudin, B. G. (2000) Zdorov'e: fakt, norma i tsennost' [Health: Fact, norm and value]. Mir psikhologii, no. 1 (21), pp. 54-68. (In Russ.).

Yudin, B. G. (2011) Chelovek kak ob"ekt tekhnologicheskikh vozdeistvii [Human being as a subject to technological interventions]. Chelovek, no. 3, pp. 520. (In Russ.).

Cohen, S. (2019) The logic of the interaction between beneficence and respect for autonomy. Medicine, Health Care and Philosophy, vol. 22, issue 2, pp. 297-304. DOI: $10.1007 / \mathrm{s} 11019-018-9876-4$

Jonsen, A. R. (2004) The history of bioethics as a discipline. In: Handbook of bioethics: Taking stock of the field from a philosophical perspective / ed. by G. Khushf. New York ; Boston ; Dordrecht ; London ; Moscow : Kluwer Academ- 
ic Publishers. 573 p. Pp. 31-51. (Philosophy and Medicine, vol. 78). DOI: 10. 1007/1-4020-2127-5_2

Miah, A. (2004) Genetically modified athletes: Biomedical ethics, gene doping and sport. London; New York : Routledge. xviii, 208 p.

Miah, A. (2008) Paralympics 2.0. Professor Andy Miah, June 6. [online] Available at: https://andymiah.net/blog/2008/06/06/paralympics-20 [archived in WaybackMachine] (accessed 12.08.2019).

Submission date: 14.08.2019.

Белялетдинов Роман Рифатович - кандидат философских наук, младший научный сотрудник сектора гуманитарных экспертиз и биоэтики Института философии Российской академии наук. Адрес: 109240, Россия, г. Москва, ул. Гончарная, д. 12, стр. 1. Тел.: +7 (495) 697-90-67. Эл. адрес: ㅁman_rb@iph.ras.ru

Belyaletdinov Roman Rifatovich, Candidate of Philosophy, Junior Research Fellow, Department of Humanitarian Expertise and Bioethics, Institute of Philosophy, Russian Academy of Sciences. Postal address: Bldg. 1, 12, Goncharnaya St., 109240 Moscow, Russian Federation. Tel.: +7 (495) 697-90-67. E-mail: $\underline{\text { ro- }}$ man_rb@iph.ras.ru

ORCID: 0000-0003-1420-0022

SPIN-код: $\underline{8323-8660}$

Попова Ольга Владимировна - доктор философских наук, ведущий научный сотрудник, руководитель сектора гуманитарных экспертиз и биоэтики Института философии Российской академии наук. Адрес: 109240, Россия, г. Москва, ул. Гончарная, д. 12, стр. 1. Тел.: +7 (495) 697-91-09. Эл. адpec: J-9101980@yandex.ru

Popova Olga Vladimirovna, Doctor of Philosophy, Leading Researcher, Head of Department of Humanitarian Expertise and Bioethics, Institute of Philosophy, Russian Academy of Sciences. Postal address: Bldg. 1, Goncharnaya St., 12, 109240 Moscow, Russian Federation. Tel.: +7 (495) 697-91-09. E-mail: J-9101980@yandex.ru

ResearcherID: $\underline{\mathrm{U}-9759-2017}$

ORCID: 0000-0002-3825-7544

SPIN-код: $\underline{4085-4783}$ 
Для циитирования:

Белялетдинов Р. Р., Попова О. В. Биотехнологии, тело и спорт: где границы свободы? [Электронный ресурс] // Горизонты гуманитарного знания. 2019. № 4. C. 48-62. URL: http://journals.mosgu.ru/ggz/article/view/1060 (дата обращения: дд.мм.гггг). DOI: 10.17805/ggz.2019.4.4 